13

\title{
Влияние электронного насыщения таммовских уровней на автоэмиссионные свойства кристаллов кремния
}

\author{
(C) P.K. Яфраров
}

Саратовский фрилиал Института радиотехники и электроники им. В.А. Котельникова РАН, 410019 Саратов, Россия

e-mail: pirpc@yandex.ru

(Поступило в Редакцию 23 декабря 2016 г.)

Показано влияние плазмохимической модификации морфологии и состава поверхностной фазы на автоэмиссионные свойства кристаллов кремния. Установлено, что электронное насыщение таммовских уровней в процессе получения атомно-чистых поверхностей кристаллов кремния и стабилизирующая пассивация поверхностных атомов в высокоионизованной микроволновой плазме с использованием хладона-14 позволяет по сравнению с пластинами с естественным оксидным покрытием или после их ионно-физического травления в среде аргона более чем в два раза уменьшить пороги напряженности электрического поля, при которых начинается полевая эмиссия электронов, и более чем на порядок увеличить максимальные плотности автоэмиссионных токов. Рассмотрены физико-химические механизмы, ответственные за модификацию поверхности и автоэмиссионных характеристик кристаллов кремния.

DOI: $10.21883 /$ JTF.2017.10.45004.2146

\section{Введение}

В вакуумной микроэлектронике одним из наиболее привлекательных материалов для полевых источников электронов при создании активной элементной базы остается кристаллический кремний. В первую очередь это обусловлено развитой технологической базой, а также обнаруженными люминесцентными свойствами нанокристаллического кремния, которые позволяют надеяться на создание в будущем сверхбыстродействующих радиационно стойких кремниевых интегральных схем с оптической связью.

Недостатками полевых источников электронов на основе кремния являются высокая чувствительность к состоянию поверхности и низкие плотности автоэмиссионных токов, которые, как правило, находятся в интервале 50-150 $\mu \mathrm{A} / \mathrm{cm}^{2}$. Так, в работе [1] сотрудников Массачусетского технологического института для плотного массива эмиттеров в виде высокоаспектных пиков из кремния $n$-типа, созданных с помощью микротехнологии, получены значения максимальной плотности автоэмиссионного тока $J=145 \mu \mathrm{A} / \mathrm{cm}^{2}$ при напряженности поля анода $E=32 \mathrm{~V} / \mu \mathrm{m}$. Однако использование высокоаспектных эмиттеров, а также различных конструктивных решений, направленных на повышение фактора усиления поля $\beta$ путем уменьшения радиусов эмитирующих острий, диаметров отверстий в управляющих электродах или создания нанолезвийных планарных структур, приводит к усложнению технологии изготовления и сопровождается, как правило, снижением надежности и увеличением себестоимости автоэмиссионных устройств [1,2]. В связи с этим большой как фундаментальный, так и прикладной интерес представляют исследования альтернативных путей, направленных на повышение воспроизводимости и улучшение эмисси- онных характеристик автокатодов, которые были бы связаны не только с конструктивными, но и с физикохимическими модификациями эмитирующих поверхностей кремниевых кристаллов.

Целью работы являлись исследования возможности плазмохимической модификации морфологии и автоэмиссионных свойств полевых источников электронов, изготовленных на основе кристаллов кремния.

\section{1. Методика и результаты экспериментов}

Эксперименты по модификации поверхностных свойств кристаллов кремния проводились в установке с использованием СВЧ ионно-плазменного источника на частоте $2.45 \mathrm{GHz}$ [3]. Мощность СВЧ излучения и индукция магнитного поля составляли соответственно $250 \mathrm{~W}$ и $875 \mathrm{G}$. В качестве рабочих газов для плазменного удаления естественного оксидного покрытия на кремнии использовались хладон-14 и аргон. Давление газов в процессах обработки было равным 0.1 Ра. В экспериментах использовались пластины монокристаллического кремния $\mathrm{Si}$ (100) электронного типа проводимости с удельным сопротивлением $0.01-0.02 \Omega \cdot \mathrm{cm}$. Величины ускоряющих напряжений $\left(U_{s m}\right)$ на подложкодержателе были фиксированными и равными -100 и $+100 \mathrm{~V}$ в процессах плазмохимического травления в среде хладона-14 и $-100 \mathrm{~V}$ при ионно-физическом травлении с использованием аргона. Глубина стравленного слоя составляла во всех случаях около $100 \mathrm{~nm}$. В качестве контрольных образцов для сравнения автоэмиссионных характеристик использовались пластины кремния с естественным оксидным покрытием. Измерения морфологических характеристик поверхностей как до 


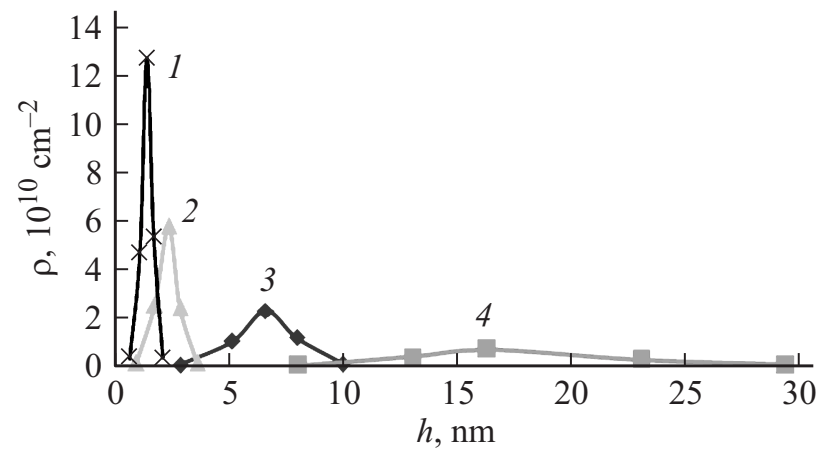

Рис. 1. Распределения поверхностных плотностей высот выступов на кремнии $n$-типа до (2) и после травления в плазме аргона (1) и хладона-14 при $U_{\mathrm{sm}}=-100(3)$ и $100 \mathrm{~V}(4)$.

травления, так и после травления кремния проводились с использованием сканирующего атомно-силового микроскопа (АСM) Solver-P-47. В качестве зондов использовались стандартные кремниевые кантилеверы CSG10 пирамидальной формы с радиусом закругления $10 \mathrm{~nm}$ и жесткостью $0.1 \mathrm{~N} / \mathrm{m}$. Поле сканирования составляло $3 \times 3 \mu \mathrm{m}$ при шаге сканирования $8 \mathrm{~nm}$ и шаге ЦАП пьезосканера по оси $Y$ равном $0.24 \mathrm{~nm}$. Схема регистрации отклонения кантилевера обеспечивает разрешение $0.1 \mathrm{~nm}$ при шаге АЦП пьезосканера по оси $Z$, равном $0.05 \mathrm{~nm}$. Обработка результатов измерений производилась с использованием программного обеспечения этого микроскопа. Автоэмиссионные свойств исследовались в условиях высокого вакуума $\left(10^{-5} \mathrm{~Pa}\right)$ на диодной структуре, позволяющей изменять расстояние между электродами с точностью до $1 \mu \mathrm{m}$.

На рис. 1 приведены распределения поверхностных плотностей высот выступов на пластинах кремния $n$-типа до и после их плазменного травления при различных смещениях в среде хладона-14 и аргона. Видно, что пластины после низкоэнергетичного ионно-физического травления с использованием аргона имеют наименьщую высоту выступов и наибольшую их поверхностную плотность, а наибольшую высоту, которая превосходит исходную более чем в 7 раз, и наименьшую поверхностную плотность, имеют пластины после травления в плазме хладона-14 при положительном смещении. Соответствующие АСМ-изображения морфологии пластин приведены на рис. 2.

В таблице приведены морфологические и автоэмиссионные характеристики пластин кремния (100) n-типа с естественным оксидным покрытием и после травления в плазме различных газовых сред и напряжений смещения. Усредненое расстояние между выступами получено расчетом из соответсвующих поверхностных плотностей. За порог начала автоэмиссии принята напряженность поля, при которой плотности автоэмиссионных токов превышали $40 \mu \mathrm{A} / \mathrm{cm}^{2}$. На рис. 3 построены зависимости параметров автоэмиссии от высоты и расстояния между выступами на исходных пластинах кремния и после травления в плазме различных газовых сред. Из приведенных экспериментальных данных видно, что при плазменной обработке в среде хладона-14 существенно увеличиваются максимальные автоэмиссионные токи при одновременном уменьшении порогов автоэмиссии. Большое влияние на автоэмиссионные характеристики оказывает знак потенциала смещения на подложкодержателе. Порог автоэмиссии при положительном смещении уменьшается по сравнению с автоэмиссией с исходных пластин кремния с естественным оксидным покрытием более чем в два раза. Максимальная плотность тока автоэмиссии практически на порядок превышает максимальную плотность тока после обработки пластин в плазме аргона.

\section{2. Обсуждение результатов}

\section{1. Формирование морфологии поверхности кристаллов кремния при микроволновом плазмохимическом травлении}

В случае использования плазмы аргона травление пластин кремния с естественным оксидным покрытием осуществляется по ионно-физическому механизму за счет распыления поверхностных атомов кремния и частиц его естественного окисла ускоренными ионами. При наклонном падении ионов на поверхность мишени скорость травления определяется выражением

$$
V(\alpha)=6.25 \cdot 10^{25}\left[\frac{j_{i} S(\alpha) A}{N_{A} \rho}\right] \cos \alpha,
$$

где $A$ - атомный вес распыляемого материала, g/mol; $N_{A}$ - число Авогадро, at $/ \mathrm{mol} ; \rho$ - плотность материала, $\mathrm{g} / \mathrm{cm}^{3} ; j_{i}$ - плотность ионного тока в сечении, перпендикулярном направлению поступления ионов, $\mathrm{A} / \mathrm{cm}^{2}$; $S(\alpha)$ - коэффициент распыления материала при угле падения ионов $\alpha$ относительно нормали к поверхности.

Практически у всех материалов с увеличением угла падения ионов на поверхность от $0^{\circ}$ до $60-70^{\circ}$ наблюдается увеличение коэффициента распыления, которое в случае травления окислов кремния может достигать пятикратного значения относительно нормального падения ионов аргона [4]. За счет различной интенсивности распыления, обусловленной статистической неоднородностью геометрии и толщины стенок углублений, и релаксации упругих напряжений в поверхностном слое пластины выступы с наибольшим углом наклона граней при увеличении длительности обработки постепенно исчезают. Это приводит к уменьшению и выравниванию высот выступов, вследствие чего их максимальная поверхностная плотность по отношению к исходной поверхности кремния с естественным оксидным покрытием увеличивается (рис. 1, кривая 1 ).

При плазмохимическом травлении кристаллов кремния в среде $\mathrm{CF}_{4}$ вид, плотность потока и энергия заряженных частиц (электронов и химически активных 

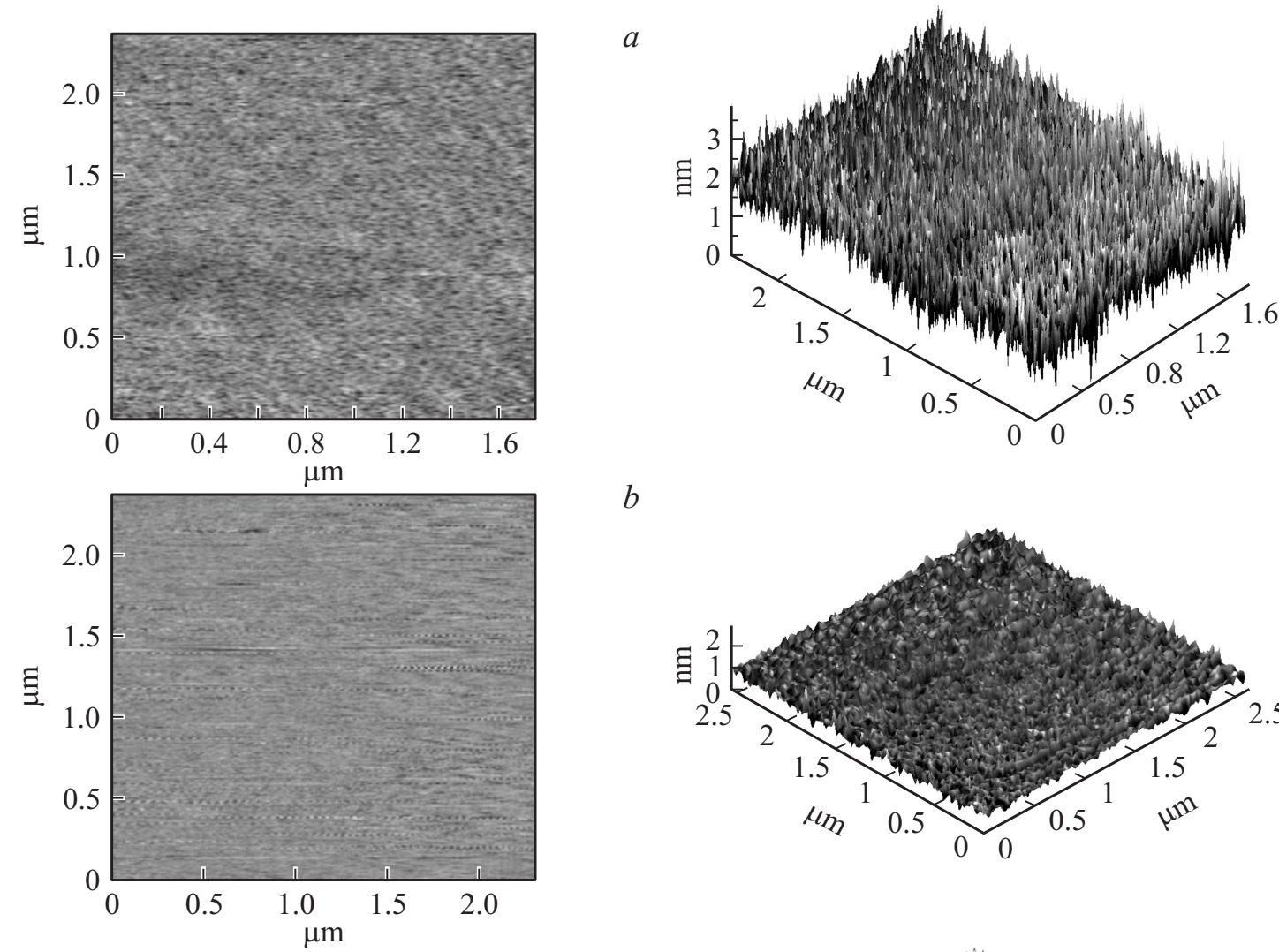

$b$
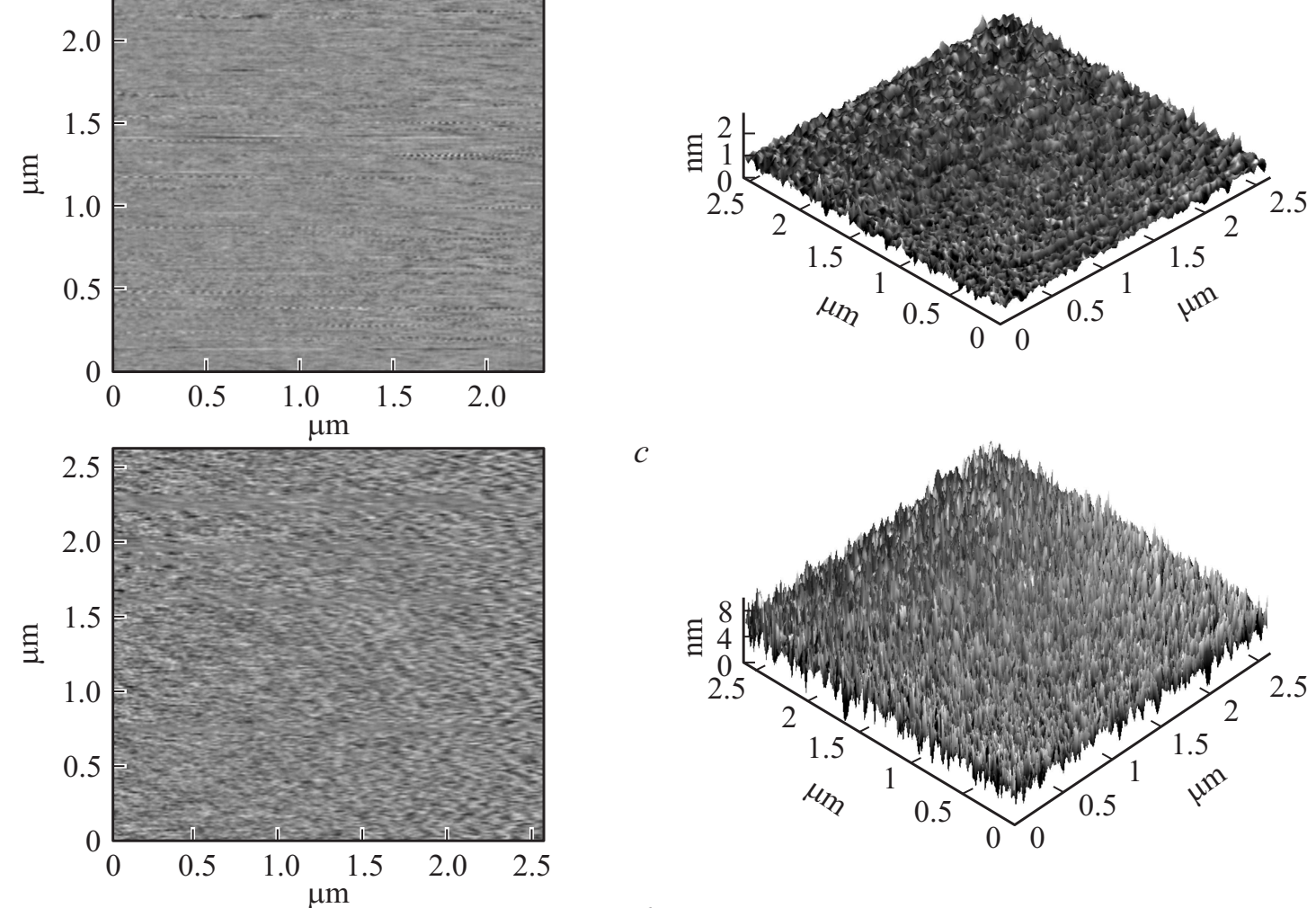

c
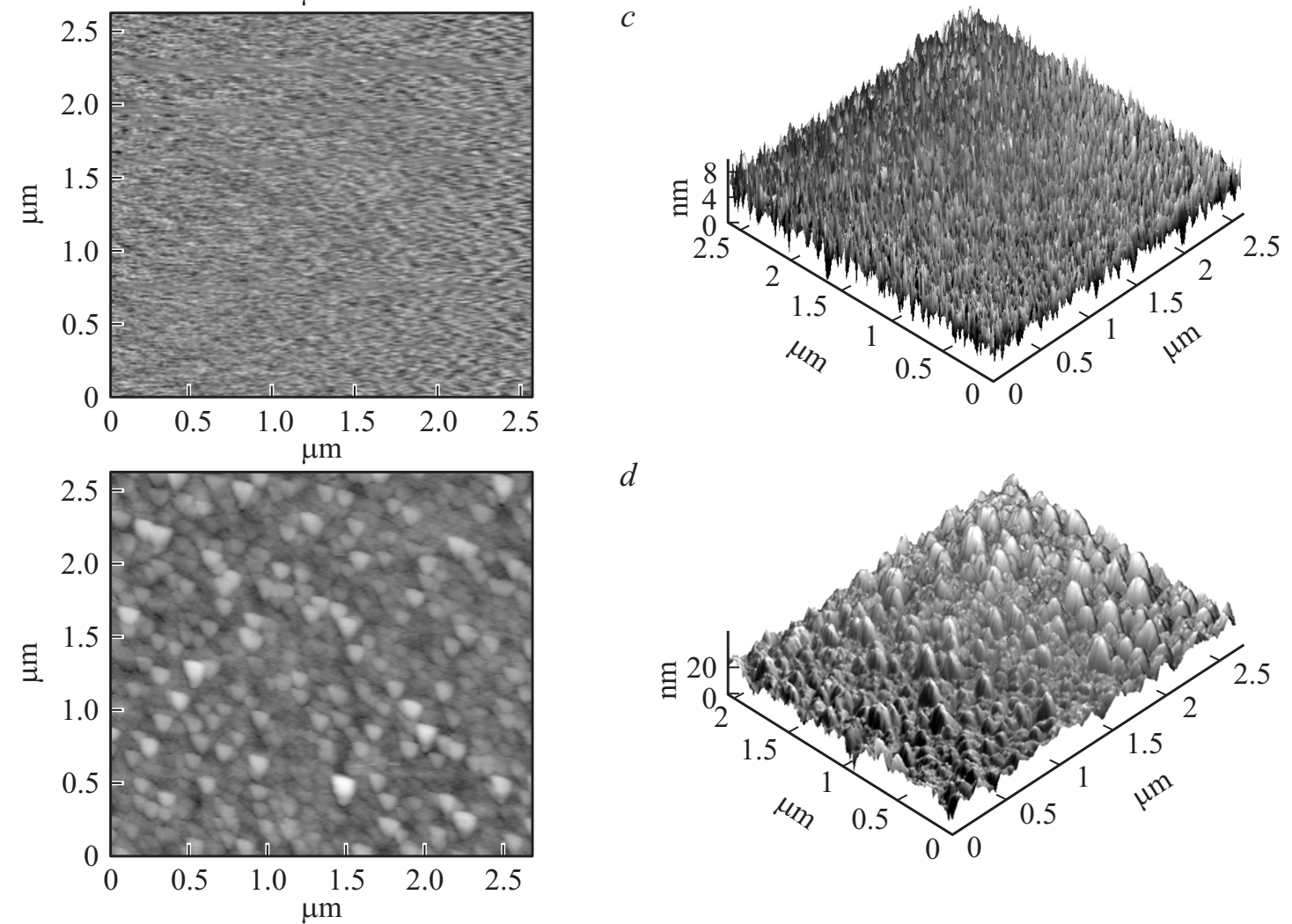

$d$

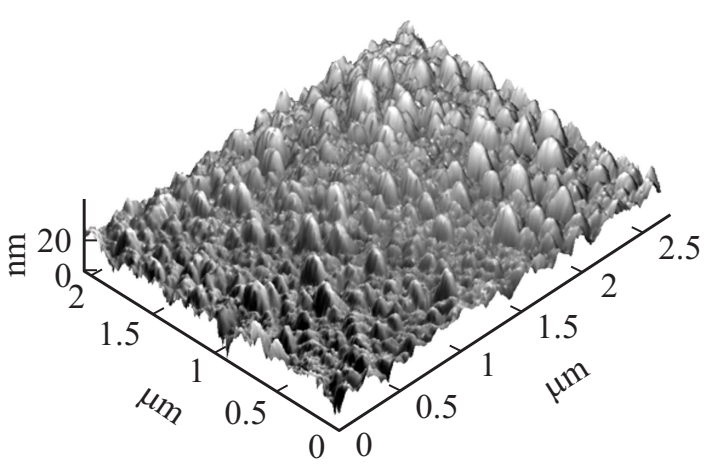

Рис. 2. АСМ-изображения поверхности кристаллов кремния $n$-типа до $(a)$ и после $(b)$ травления в плазме аргона и хладона-14 при $U_{\mathrm{sm}}=-100(c)$ и $100 \mathrm{~V}(d)$. 

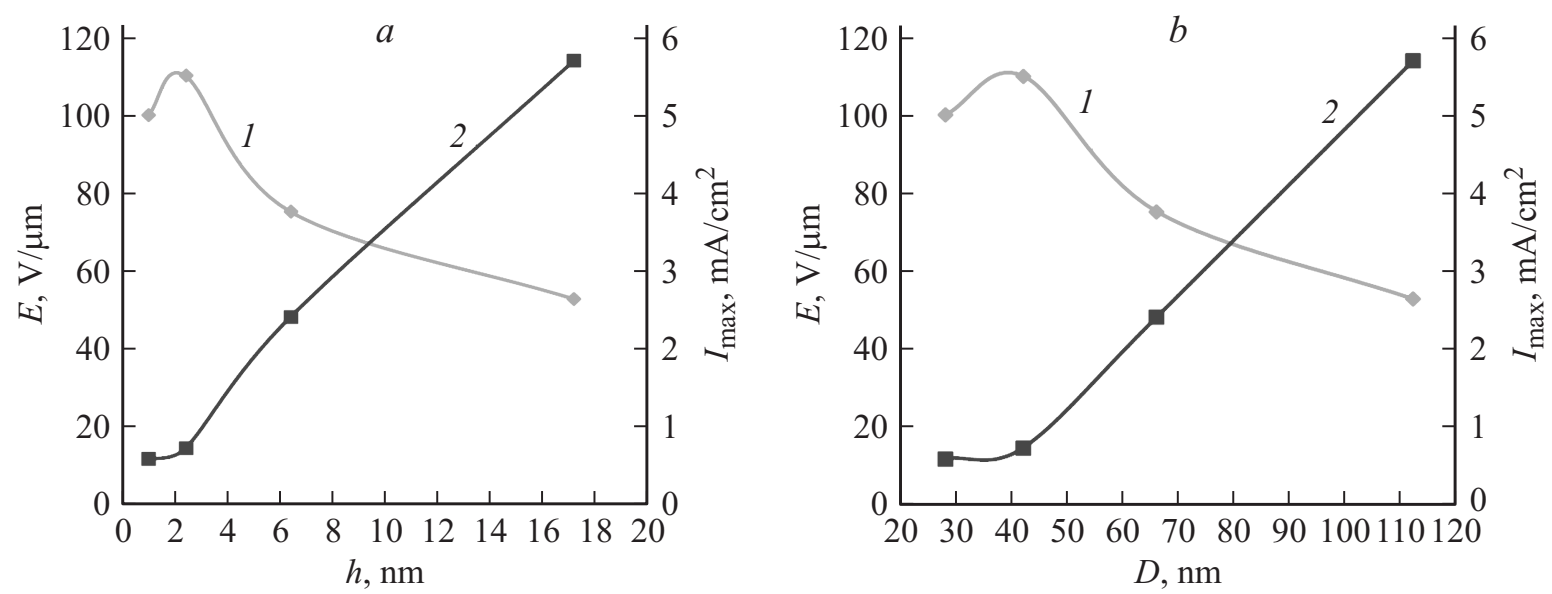

Рис. 3. Зависимости напряженностей электрического поля порога (1) и максимальных плотностей токов (2) автоэмиссии пластин кремния (100) $n$-типа от высоты $(a)$ и расстояния между выступами $(b)$ до и после плазменного травления в различных газовых средах.

Влияние смещения и среды плазменной обработки на параметры морфологии и автоэмиссии кристаллов кремния (100) $n$-типа проводимости

\begin{tabular}{l|c|c|c|c}
\hline \multirow{2}{*}{ Режим плазменной обработки } & \multicolumn{2}{|c|}{ Хладон-14 } & Аргон & \multirow{2}{*}{ Без обработки } \\
\cline { 2 - 4 } & $-100 \mathrm{~V}$ & $+100 \mathrm{~V}$ & $-100 \mathrm{~V}$ & \\
\hline Высота выступов $h, \mathrm{~nm}$ & 6.4 & 17.2 & 1.0 & 2.4 \\
Плотность выступов $\rho \cdot 10^{10}, \mathrm{~cm}^{-2}$ & 2.3 & 0.8 & 12.8 & 5.8 \\
Расстояние между выступами $D, \mathrm{~nm}$ & 66 & 112 & 28 & 42 \\
$E, \mathrm{~V} / \mu \mathrm{m}$ & 75 & 52.5 & 100 & 110 \\
$J_{\max }, \mathrm{mA} / \mathrm{cm}^{2}$ & 2.4 & 5.7 & 0.6 & 0.7
\end{tabular}

ионов), поступивших на поверхность, зависят от величины и знака потенциала смещения на подложкодержателе. Интегральным результатом протекания гетерогенных химических реакций между поверхностными атомами и структурными частицами плазмы является ослабление связей поверхностных атомов кремния с подложкой и их удаление в результате образования летучих продуктов реакций в виде $\mathrm{SiF}_{4}$-соединений и активированной десорбции $\mathrm{SiF}_{2}$-комплексов под воздействием электронноионной бомбардировки [3].

При отрицательном смещении на подложкодержателе основными химически активными частицами бомбардирующими поверхность кремния являются положительные ионы $\mathrm{C}^{+}, \mathrm{CF}_{n}^{+}$, где $n=1-4$, а также радикалы $\mathrm{CF}_{n}$ и нейтральные атомы фтора, углерода и $\mathrm{CF}_{4}$. При положительном смещении, кроме радикалов $\mathrm{CF}_{n}$, молекул хладона-14 и атомов фтора, основными заряженными компонентами плазмы, поступающими на поверхность кремния, являются электроны и отрицательные ионы фтора.

Поступление из плазмы двух видов частиц - нейтральных и ионизированных - определяет и два вида их взаимодействия с поверхностными атомами кремния: гетерогенные химические реакции с образованием летучих соединений и физические эффекты, связанные с ионной и/или электронной бомбардировкой. При СВЧ плазменной обработке с давлениями рабочих газов около $0.1 \mathrm{~Pa} \mathrm{реализуется} \mathrm{режим} \mathrm{слабой} \mathrm{адсорбции,} \mathrm{который}$ характеризуется низкой степенью заполнения поверхности адсорбированными газовыми частицами. В режиме слабой адсорбции при плазмохимическом травлении с отрицательным смещением наиболее вероятным является процесс, при котором ускоренный электрическим смещением углеродосодержащий ион вида $\mathrm{CF}_{n}^{+}$, где $n=0-4$, при ударе о поверхность диссоциирует на атомы углерода и фтора (ионно-индуцированная или ударная диссоциация молекулярного иона [3]), которые затем активно взаимодействуют с поверхностными атомами кремния и его оксидного покрытия:

$$
\mathrm{CF}_{n}^{+}+\mathrm{Si} \rightarrow \mathrm{C}_{\mathrm{ads}}+n \mathrm{~F}^{0}+\mathrm{Si}
$$

При положительном смещении на подложкодержателе бомбардировка поверхности кремния положительными углеродосодержащими ионами практически отсутствует. В этом случае наиболее вероятным является механизм травления, при котором ускоренные полем подложкодержателя электроны осуществляют гетерогенную диссоциацию и ионизацию адсорбированных молекул и радикалов рабочего газа с взаимодействием последних с поверхностными атомами оксида кремния и обра- 
зующейся атомно-чистой поверхности. Из-за низкого коэффициента аккомодации, обусловленного большим различием масс атомов и электронов, кинетическая энергия, передаваемая атому или молекуле при столкновении с электроном, достаточно мала. Это снижает скорость активации и десорбции атомов адсорбата и низколетучих продуктов химических реакций. Результирующая скорость плазмохимического травления кремния при $U_{s m}=+100 \mathrm{~V}$ составляет около $5.1 \mathrm{~nm} / \mathrm{min}$. Она более чем в 4 раза меньше скорости травления при $U_{s m}=-100 \mathrm{~V}$, которая составляет $21.3 \mathrm{~nm} / \mathrm{min}$.

На начальных стадиях травления адатомы углерода на поверхности участвуют в восстановлении $\mathrm{SiO}_{2}$ с образованием летучих соединений его окислов:

$$
\mathrm{C}+\mathrm{SiO}_{2} \rightarrow \mathrm{CO}_{2} \uparrow+\mathrm{Si} .
$$

После удаления оксидного слоя ненасыщенные связи поверхностных атомов кремния пассивируются в результате хемосорбции как атомами углерода с образованием $\equiv \mathrm{Si}-\mathrm{CF}_{m}$, где $m=0-3$, ковалентных связей между кремнием и углеродом с энергией $4.55 \mathrm{eV}$, так и атомами фтора с образованием более устойчивых и вы-

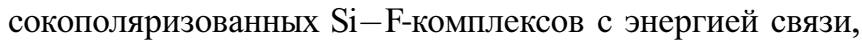
равной $5.6 \mathrm{eV}$, ориентированных нормально поверхности кремния, согласно реакции

$$
\mathrm{R} \equiv \mathrm{Si}^{*}+\mathrm{F} \rightarrow \mathrm{R} \equiv \mathrm{Si}-\mathrm{F},
$$

где $\mathrm{R}$ - кристаллическая решетка кремния.

Наиболее вероятными механизмами удаления комплексов $\mathrm{Si}-\mathrm{F}$ с поверхности кремния, в результате которого осуществляется травление, являются [3]: 1 - образование адкомплексов $\mathrm{SiF}_{2}$, которые уже сравнительно легко (пороговая энергия радиационно-стимулированной десорбции для них составляет доли $\mathrm{eV}$ ) могут быть десорбированы с поверхности кремния последующим ионным ударом, и 2 - образование легко летучего соединения $\mathrm{SiF}_{4}$ в результате взаимодействия двух адкомплексов $\mathrm{SiF}_{2}$ между собой.

При первом механизме удаления комплексов $\mathrm{Si}-\mathrm{F}$ c поверхности кремния скорость ионно-индуцированного травления $\left(V_{j}\right)$ пропорциональна плотности ионного тока на подложку и степени заполнения поверхности адкомплексами $\mathrm{SiF}_{2}$ [3]:

$$
V_{j}=K j \theta \alpha,
$$

где $K-$ коэффициент распыления, т.е. вероятность десорбции комплекса $\mathrm{SiF}_{2}$ при попадании в него иона, $j$ - поток ионов фтора на поверхность кристалла, $\theta-$ степень заполнения поверхности адкомплексами $\mathrm{SiF}_{2}$, $\alpha=M /\left(N_{0} \rho\right), M$ - молярная масса кремния, $\rho$ - плотность, $N_{0}$ - число Авогадро. В этом механизме преобладающим является образование на поверхности кремния после окончания процесса $\equiv \mathrm{Si}-\mathrm{CF}_{m}, \equiv \mathrm{Si}-\mathrm{CF}_{2}-\mathrm{Si} \equiv$ и др. фторуглеродных комплексов [5].

Другой механизм удаления поверхностных атомов кремния в виде легко летучего соединения $\mathrm{SiF}_{4}$ является преимущественным в случае высокой степени заполнения поверхности адкомплексами $\mathrm{SiF}_{2}$. Он реализуется при положительном смещении и обусловлен отсутствием ионной бомбардировки и неоднородностью распределения химического адсорбата по поверхности кремния. Наибольшая его концентрация реализуется в углублениях рельефа поверхности, где свободная энергия системы поверхность-плазма имеет минимальные значения. В условиях интенсивной электронной бомбардировки, которая осуществляет гетерогенную активацию химического адсорбата и подложки, это повышает степень заполнения адкомплексами $\mathrm{SiF}_{2}$ и увеличивает скорость растравливания углублений в результате изотропного по своей природе химического процесса, связанного с образованием летучего соединения $\mathrm{SiF}_{4}$. В этом случае скорость спонтанного, изотропного по своей природе процесса пропорциональна квадрату степени заполнения поверхности кремния адкомплексами $\mathrm{SiF}_{2}$ [3]:

$$
V_{S} \approx \theta^{2}
$$

С увеличением длительности травления за счет бокового растрава стенок между отдельными углублениями поверхностная плотность выступов уменьшается, а их высоты увеличиваются (рис. 1, кривые 3,4 ).

\section{2. Взаимосвязь морфологии и автоэмиссионных свойств кристаллов кремния}

Поверхность кремния легко окисляется, при экспозиции кремниевой подложки в атмосфере происходит быстрое формирование окисной пленки. Основной процесс, происходящий при этом, заключается в перераспределении валентных электронов между кремнием и кислородом с выделением большого количества тепла. Константа скорости роста окисла связана с кинетикой протекания реакции на границе раздела фаз и зависит от скорости, с которой атомы кремния переходят в окисную фазу. Поэтому скорость реакции окисления кремния лимитируется плотностью разорванных $\mathrm{Si}-\mathrm{Si}$-связей подложки. В процессе ионно-физического распыления естественного оксидного покрытия и поверхностных слоев кремния ионами аргона плотность разорванных связей на кремнии существенно увеличивается. Это повышает реакционную способность поверхностных атомов кремния и способствует активному формированию оксидного покрытия как в процессе распыления атомов кремния за счет кислорода остаточной атмосферы вакуумной камеры, так и после извлечения образцов на атмосферу.

В связи с аморфизацией и интенсивным образованием оксидного покрытия пороги начала автоэмиссии пластин кремния после травления в низкоэнергетичной плазме аргона хотя и уменьшаются за счет уменьшения толщины оксидного покрытия по сравнению с исходными пластинами с естественным оксидным покрытием, но очень не значительно. Несмотря на снижение порогов 
автоэмиссии, максимальные плотности токов уменьшаются с $0.7 \mathrm{~mA} / \mathrm{cm}^{2}$ при автоэмиссии с кремниевых пластин с естественным покрытием до $0.6 \mathrm{~mA} / \mathrm{cm}^{2}$ после сухого травления в плазме аргона (рис. $3, b$ ). Согласно представлениям Фаулера-Нордхейма, это может быть обусловлено геометрическими факторами, связанными со снижением коэффициентов усиления поля $\beta$ на отдельных эмитирующих выступах и их взаимной экранировкой.

Коэффициент $\beta$ определяет величину электрического поля на отдельном (усредненном) микровыступе поверхности автокатода и при прочих одинаковых условиях, согласно закону Фаулера-Нордхейма, нелинейным образом определяет величину плотности тока автоэмиссии [6]:

$$
j=A \frac{\left(E_{a v} \beta\right)^{2}}{\varphi} \exp \left(-\frac{B \varphi^{3 / 2}}{E_{a v} \beta}\right),
$$

где $A, B$ - некоторые коэффициенты, $\varphi$ - работа выхода электрона из материала, $E_{a v}-$ средняя величина напряженности внешнего электрического поля, которая через коэффициент $\beta$ определяет напряженность поля на отдельном (усредненном) микровыступе пленочной структуры по формуле

$$
E_{m p}=\beta E_{a v} .
$$

Из электростатического рассмотрения следует, что коэффициент $\beta$ в первом приближении линейно связан с высотой микровыступов и зависит от их поверхностной плотности (расстояния между выступами). С увеличением последней выше некоторого значения, зависящего от высоты выступов, величина $\beta$ начинает уменьшаться из-за экранирования внешнего электрического поля соседними выступами. Это снижает напряженность электрического поля на вершинах эмиссионных центров и для возобновления автоэмиссии требует увеличения напряженности внешнего электрического поля. Порог напряженности электрического поля начала автоэмиссии при этом увеличивается. Одновременно с этим, согласно выражению (7), с уменьшением $\beta$ уменьшается плотность тока автоэмиссии. Эти представления коррелируют с изменением морфологии поверхности кремния после травления в плазме аргона: меньшей высотой эмитирующих выступов и более высокой их поверхностной плотностью по сравнению с поверхностью исходной пластины с естественным оксидным покрытием.

Различие в преобладающих механизмах плазмохимического травления в хладоне-14 при различных знаках потенциалов смещения на подложкодержателе обусловливает различные морфологические характеристики поверхностей кристаллов кремния. При травлении с положительным смещением за счет отсутствия ионного распыления поверхностных атомов кремния и преобладания изотропного электронно-радикального травления с образованием $\mathrm{SiF}_{2}$ и $\mathrm{SiF}_{4}$-комплексов высоты выступов рельефа поверхности увеличивается по сравнению с травлением при отрицательном смещении от 6.4 до $17.2 \mathrm{~nm}$. Одновременно с этим уменьшаются поверхностные плотности выступов от $2.3 \cdot 10^{10} \mathrm{~cm}^{-2}$ до $0.8 \cdot 10^{10} \mathrm{~cm}^{-2}$ и соответственно увеличивается среднее расстояние между ними от 66 до $112 \mathrm{~nm}$. В соответствии с этим улучшается геометрический фактор поверхности кремния: увеличивается коэффициент усиления поля автоэмиссии на эмитирующих выступах и уменьшается взаимная экранировка выступами внешнего электрического поля. Это способствует уменьшению порогов автоэмиссии и увеличению плотностей автоэмиссионных токов (рис. 3).

\section{3. Влияние дипольных моментов поверхности на автоэмиссионные свойства кристаллов кремния}

Анализ зависимостей, приведенных на рис. 3, показывает, что при плазмохимическом травлении кристаллов кремния в среде хладона-14 независимо от знака смещения на подложкодержателе наблюдается практически линейная взаимосвязь между высотами выступов и расстояниями между ними, одной стороны, и порогами напряженностей полей автоэмиссии и максимальными плотностями токов, с другой. Такой характер корреляции порогов автоэмиссии и максимальных плотностей токов через коэффициент усиления поля $\beta$ не соответствует выражению (7), в котором взаимосвязь между этими параметрами должна описываться не обратно пропорциональной, а экспоненциальной функцией. Причина этого состоит в следующем.

При травлении пластин кремния с естественным оксидным покрытием в плазме хладона-14 с различным знаком смещения на подложкодержателе, образующиеся после травления $\mathrm{Si}-\mathrm{CF}_{m}, \mathrm{Si}-\mathrm{F}$ и другие фторосодержащие углеродные и кремниевые комплексы препятствует возникновению и росту со временем за счет диффузии кислорода диэлектрического потенциального барьера на атомно-чистой поверхности кристаллов кремния в виде оксидов различного стехиометрического состава. Однако их образование, так же как любой другой химический адсорбат, изменяет работу выхода электронов за счет изменения дипольного момента поверхности [7].

Из-за высокой электроотрицательности фтора увеличение дипольного момента особенно сильно в случае

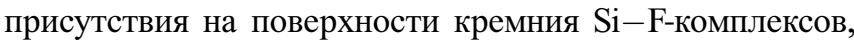
которое реализуется при травлении в плазме хладона14 с положительным смещением на подложкодержателе. Для перемещения электрона через образовавшийся дипольный слой необходимо совершить дополнительную работу. Это приводит к росту работы выхода по сравнению с атомно-чистой поверхностью кремния и отсутствию нелинейной взаимосвязи между коэффициентом усиления поля и плотностью автоэмиссионого тока. Благодаря отсутствию диэлектрического барьера в виде оксидов кремния с одновременным улучшением геометрического фактора автоэмиссионной поверхности 
и обогащением поверхностных состояний электронами в результате нейтрализации заряда донорных центров поверхностных атомов кремния с ненасыщенными химическими связями максимальльная плотность автоэмиссионного тока увеличивается по сравнению с кремнием с естественным оксидным покрытием от 0.7 до $5.7 \mathrm{~mA} / \mathrm{cm}^{2}$, а порог автоэмиссии уменьшается более чем в 2 раза.

При отрицательных смещениях на подложкодержателе в условиях ограниченного поступления на поверхность кремния отрицательных ионов фтора и электронов преобладающими являются $\equiv \mathrm{Si}-\mathrm{CF}_{m} \equiv$, а также $\equiv \mathrm{Si}-\mathrm{C}=\mathrm{CF}_{m}$-комплексы, которые на границе с кремнием образуют монослой карбида кремния с фторуглеродной диэлектрической поверхностной фазой. Он препятствует проникновению электрического поля в полупроводник, с одной стороны, и препятствует выходу носителей из подложки, с другой. Величина барьера зависит от толщины диэлектрического слоя. В результате этого автоэмиссия с поверхности, так же, как в случае с естественным оксидным покрытием, будет осуществляться за счет двуступенчатого туннелирования электронов из зоны проводимости кремния через карбид-кремниевый диэлектрический барьер во фторуглеродную поверхностную фазу и затем в вакуум. Вероятность такого туннелирования существенно ниже, чем в случае образования монослойных $\mathrm{Si}-\mathrm{F}$-комплексов при травлении кремния в хладоне-14 с положительным смещением (см. таблицу). Кроме того, носители, инжектированные из кремниевой подложки в $\mathrm{Si}-\mathrm{CF}_{m}$ поверхностный слой, взаимодействуют с дефектами, расположенными в его объеме. Результатом этого взаимодействия является захват носителей на ловушечные центры, который приводит к дополнительному увеличению порога автоэмиссии. Пороги начала автоэмиссии при травлении кремния в плазме хладона-14 с отрицательным смещением увеличиваются по сравнению с плазмохимическим травлением в том же составе рабочего газа при положительном смещении до $75 \mathrm{~V} / \mu \mathrm{m}$, а максимальные плотности токов уменьшаются до $2.4 \mathrm{~mA} / \mathrm{cm}^{2}$.

\section{Заключение}

Низкоэнергетичная СВЧ плазменная микрообработка в зависимости от режима воздействия и состава рабочего газа позволяет различным образом модифицировать („перестраивать“) наноморфологию гетероструктурной поверхности пластин кремния (100) с естественным оксидным покрытием и ее автоэмиссионные свойства. Пороги начала автоэмиссии и максимальные плотности автоэмиссионных токов решеток эмиттеров на пластинах кремния $n$-типа, кроме традиционной зависимости от коэффициента усиления поля на эмитирующих выступах, определяются также составом, толщиной и суммарным дипольным моментом образующейся после процесса травления поверхностной фазы. Использова- нием режимов плазмохимического травления с монослойным фторированием образующейся атомно-чистой поверхности пластин кремния и насыщением ее поверхностных уровней электронами плазмы позволяет стабилизировать состав поверхностный фазы, уменьшить пороги начала автоэмиссии и увеличить максимальные плотности автоэмиссионных токов.

Исследование выполнено за счет гранта Российского научного фонда (проект № 16-19-10033).

\section{Список литературы}

[1] Velásquez-García L.F., Guerrera S., Niu Y., Akinwande A.I. // IEEE Trans. Electron Dev. (2011). Vol. 58. P. 1783.

[2] Гуляев Ю.В., Абаньшин Н.П., Горфинкель Б.И., Морев С.П., Резчиков А.Ф., Синицын Н.И., Якунин А.Н. // Письма в ЖТФ. 2013. Т. 39. Вып. 11. С. 63-70.

[3] Ябаров Р.К. Физика СВЧ вакуумно-плазменных нанотехнологий. М.: Физматлит, 2009. 216 с.

[4] Ивановский Г.Ф., Петров В.И. Ионно-плазменная обработка материалов. М.: Радио и связь, 1986. 232 с.

[5] Яфаров Р.К. // ФТП. 2015. Т. 49. Вып. 3. С. 329-335.

[6] Усанов Д.А., Яфаров Р.К. Методы получения и исследования самоорганизующихся наноструктур на основе кремния и углерода. Саратов: Сарат. гос. ун-т, 2011. 126 с.

[7] Оура К., Лифиии В.Г., Саранин А.А., Зотов А.В., Катаяма М. Введение в физику поверхности. М.: Наука, 2006. $490 \mathrm{c}$. 